\title{
Trabalhadores-intercessores no campo da Atenção Psicossocial, ou outra versão do avesso do avesso da psicanálise
}

\author{
Workers-intercessors in the field of Psychosocial Attention, or \\ another interpretation the reverse of the reverse of psychoanalysis
}

\author{
Waldir Périco ${ }^{1, *}$ (D) \\ ${ }^{1}$ Universidade do Estado do Rio de Janeiro (UERJ), Rio de Janeiro, RJ, Brasil
}

\author{
Resenha do livro \\ Costa-Rosa,A. (20 I3) Atenção Psicossocial além da Reforma \\ Psiquiátrica: Contribuição a uma Clínica Crítica dos Processos de \\ Subjetivação na Saúde Coletiva. São Paulo, SP: UNESP.
}

\begin{abstract}
Direito a convicções possui apenas aquele que, assim como eu, trabalhou muitos anos no mesmo material e viveu ele próprio repetidas vezes, as mesmas novas e surpreendentes experiências. (Freud, 1916-1917/2014, p. 326)
\end{abstract}

Lançado pela editora Unesp, o livro do professor Abílio da Costa-Rosa (2013) se apresenta como ponto de chegada - sem ser ponto final - de uma trajetória de quase quarenta anos de pesquisa, sempre a partir da práxis, cujo intuito é repensar as práticas "psi" no contexto das instituições públicas de Saúde. Seja como trabalhador do campo - inicialmente trabalhador de Saúde Mental e depois supervisor clínico-institucional - seja, mais recentemente, como professor universitário em cursos de graduação e pós-graduação formando outros trabalhadores, o autor dá genuinidade ao uso do conceito de práxis humana, bem explorado em sua convicta produção teórica. Devido a tratarse necessariamente de uma práxis nas instituições, no que se refere à "caixa de ferramentas" utilizada, além da psicanálise freudiana continuada por Lacan e da Análise Política das Instituições possibilitada pelo Materialismo Histórico, Costa-Rosa nos mostra a necessidade de implementarmos nosso caleidoscópio teórico-prático, instrumentando-nos também com a Análise Institucional francesa e conceitos da Filosofia da Diferença. O autor é psicanalista, analista institucional e professor Livre-Docente do departamento de Psicologia Clínica da Universidade Estadual Paulista Campus de Assis.

A partir desses referenciais de análise, criticando $e$ redimensionando a discussão de Tomas Khun (1978) sobre as transformações paradigmáticas no campo das práticas científicas, Costa-Rosa (2013) chega à hipótese da existência de dois paradigmas de produção clínica em permanente contraposição dialética na Saúde Mental Coletiva: o ainda hegemônico Paradigma Psiquiátrico Hospitalocêntrico Medicalizador (PPHM) e o Paradigma Psicossocial (PPS) redefinido para-além da Reforma Psiquiátrica. Munido de sua "caixa de ferramentas", a preponderância de tais paradigmas é visada segundo quatro parâmetros de análise minuciosamente imbricados, a saber: (1) a concepção do 'objeto'e dos 'meios de atuação'sobre ele; (2) as formas da organização das relações intra e interinstitucionais; (3) as formas de relacionamento com a 'clientela'e o Território; $\mathrm{e}$ (4) as formas de seus efeitos e desdobramentos terapêuticos $e$ ético-políticos. Entre esses quatro parâmetros, refere que há uma tendência à sintonia ética, caracterizando a consistência de cada um desses paradigmas. São parâmetros que nos permitem analisar a realidade do dia a dia dos Estabelecimentos de Saúde Mental, para se avaliar onde se está e poder mirar os deslocamentos necessários. Parte da

\footnotetext{
* E-mail: waldirperico@yahoo.com.br

- Submetido: 10/04/2017; Aceito: 16/10/2018.
} 
hipótese de que sem uma clareza paradigmática ficaremos em maus bocados quanto às possibilidades de interceder nos dois âmbitos dessa práxis (o clínico e o institucional), para fazer a Reforma Psiquiátrica, concebida apenas como meio caminho andado, avançar radicalmente a outro paradigma de produção de subjetividade.

No PPHM, em sintonia com a forma de concepção do 'objeto' como corpo orgânico (ou, quando muito, que é aonde se chegou com a Reforma Psiquiátrica no nosso contexto, como indivíduo consciente e "cidadão de direitos") os 'meios' de atuação pautam-se na perspectiva psicoterápico-pedagógico-disciplinar que, por mais que apareçam sob as vestes "humanizadas", desembocam em práticas de natureza opressiva (Périco, 2014); as formas da organização das relações intra e interinstitucionais se dão sob o regime político da heterogestão; em sintonia com esse regime, as formas de relacionamento com a 'clientela' e o Território se expressam nas relações hierárquicoautoritárias típicas ao princípio doença-cura (relações do tipo loucos-sãos, carente-supridor, ignorante-sapiente), sendo a instituição um lócus depositário dos "indivíduos-problemas" com pouca ou nenhuma interlocução com o Território; e $o s$ efeitos terapêuticos chegam, no máximo, ao tamponamento dos sintomas e demais impasses subjetivos, tendo como consequência ético-política a readaptação social.

No PPS, propõe-se que a forma de conceber o 'objeto' alcance a dimensão do indivíduo que inclui o sujeito do inconsciente, ou seja, as duas dimensões do 'entre', a que ele habita e a que o habita (Costa-Rosa, 2012): tanto como indivíduo cidadão "entre os homens" (lido a partir do Materialismo Histórico) quanto como sujeito do diferir desejante "entre significantes" (tal como define a psicanálise). Nesse paradigma de produção, os 'meios' de atuação deverão estar à altura da concepção do 'objeto' '. Partindo da ideia de que a instituição é mais um indispensável dispositivo de tratamento, tanto as formas da organização das relações intra e interinstitucionais, quanto as formas de relacionamento com a 'clientela' $e$ Território são consideradas fundamentais na perspectiva ética desse paradigma. Para que ocorra o equacionamento analítico dos sintomas e demais impasses subjetivos (efeitos "terapêticos") e a consequente implicação subjetiva e sociocultural crítica no laço social (efeitos ético-políticos), como pressupõe a meta do quarto parâmetro desse paradigma, essas formas de relacionamento somente poderão se pautar na horizontalidade e na perspectiva da colocação dos sujeitos (tanto os trabalhadores quanto os "sujeitos do tratamento") no lugar de protagonistas de suas ações, incluindo, no que diz respeito aos "sujeitos do

1 Aqui não temos pretendido senão estender a finalidade do Ensino de Lacan (1967-1968/2006), sobre a teoria freudiana, que se expressa em "fazer psicanalistas [nesse caso, trabalhadores sociais intercessores] à altura dessa função que se chama 'sujeito', pois se verifica que só a partir desse ponto de vista se enxerga bem aquilo de que se trata na psicanálise" (p. 53). tratamento", as ações de recuperação/maximização de seus próprios processos de subjetivar. É fim ético das práticas do Paradigma Psicossocial fazer coincidir, no mesmo sujeito, os atos de produção e apropriação.

Entre uma densa "introdução geral", que resgata a história das reformas psiquiátricas no Brasil e no mundo, e algumas "conclusões gerais", encontramos no livro oito ensaios-capítulos, cada qual tratando de um aspecto importante à clínica da Atenção Psicossocial. Como apresenta o autor:

Defini como operadores teórico-práticos gerais, com vistas a desenharem um panorama do Modo Psicossocial, os três primeiros capítulos: sobre o "conceito de Modos de Produção", sobre a "instituição como dispositivo de produção de subjetividade", e sobre a "Estratégia Atenção Psicossocial". [...] Como operadores de aspectos mais específicos do Paradigma Psicossocial, incluo os cinco capítulos seguintes sobre a interprofissionalidade, a crítica da razão medicalizadora, a psiquiatria psicossocial, o grupo psicoterapêutico, e sobre a ética da Atenção Psicossocial (Costa-Rosa, 2013, p. 10).

O autor grafa com iniciais maiúsculas o termo "atenção psicossocial" para elevá-lo ao estatuto de conceito, dandolhe um sentido radicalmente diferente, ou seja, não mais como sinônimo de "Reforma Psiquiátrica"” (Costa-Rosa, 2013). As práticas desta, se não almejam a transposição paradigmática, acabam por reproduzir "mais do mesmo" sob outras vestes. Desta forma, se a Reforma Psiquiátrica brasileira, pautada principalmente na experiência italiana, conseguiu, em relação ao PPHM, operar uma ampliação da forma de conceber o 'objeto', ao ponto de considerálo como "indivíduo cidadão" para além da concepção estritamente orgânica, uma análise rigorosa do estatuto dos efeitos ético-políticos de suas práticas nos permite ver que o resultado final desse processo de produção ainda continua sendo a adaptação social dos indivíduos ao instituído social. Esse aspecto já é suficiente para vermos como a Reforma Psiquiátrica brasileira ainda se caracteriza por ações intermediárias no que se refere ao horizonte ético desses dois paradigmas de produção clínica. À transposição paradigmática, quanto a esse aspecto, se faz necessário ampliar ainda mais a concepção do 'objeto' - bem como os 'meios' de atuação sobre ele -, ao ponto de incluir a dimensão do sujeito do inconsciente, com todas as suas consequências.

Um estudo mais detido dessa análise paradigmática mostra a forma como Costa-Rosa (2013) alinhava cuidadosamente, sem cair em "ornitorrincos epistemológicos", esses complexos campos de saberes, campos que carregam em comum - e é isso que orienta tal empreitada - o fato de

2 Apesar de já se encontrar em germe desde os primeiros trabalhos do autor (Costa-Rosa, 1987), o primeiro trabalho que versou mais detidamente sobre essa perspectiva, para o qual remeto o leitor, foi publicado em uma coletânea organizada por Paulo Amarante (Costa-Rosa, Luzio, \& Yasui, 2003). 
aspirarem à superação radical do princípio científico sujeitoobjeto e dos seus efeitos (ético-políticos) típicos. Em outro lugar (Périco, 2014), levantamos a hipótese segundo a qual o autor seguiria a indicação freudiana de que, para a ampliação da psicanálise a outros lócus de atuação, seria necessária aos operadores dessa clínica a incursão em outros campos de saberes, posto que "uma aplicação desse tipo pressupõe um conhecimento especializado, que um analista não possui, ao passo que aqueles que o possuem, os especialistas, nada compreendem da análise" (Freud, 1933/1996, p. 144, grifo nosso). Isso nos abre uma perspectiva diferente em relação à definição e à forma da imersão desses trabalhadores, paraalém, inclusive, da perspectiva clássica entre "psicanálise pura" e "psicanálise aplicada": por estratégia, entre outros motivos, não mais "psicanalistas nas instituições", mas sim "trabalhadores-intercessores" com variadas formações profissionais (psiquiatria, psicologia, serviço social, terapia ocupacional, etc) precavidos pela psicanálise do campo de Freud e Lacan, pelo Materialismo Histórico - e por seus derivados - , operando a subversão radical das suas práticas típicas ${ }^{3}$.

Está em questão virar pelo avesso tais práticas. Mas, no contexto da Saúde Mental Coletiva, quando se vira o avesso da psicanálise pelo avesso não é ao início, à psicanálise típica, que se retorna. Quando estamos nesse campo, trata-se, então, de outra versão do avesso do avesso da psicanálise. Por consequência, devemos considerar as práticas dos trabalhadores-intercessores numa perspectiva de exterioridade íntima em relação à psicanálise típica. Se Freud virou as terapêuticas autoritário-alienantes pelo avesso, para fundar a psicanálise do consultório particular e a formação de psicanalistas, quando se trata da clínica pública na Saúde Coletiva há de termos a produção de uma clínica coletiva e a formação de trabalhadores-intercessores refazendo o mesmo ato; "psicanalistas" de um novo tipo, se quisermos colocar nesses termos, que podem ser referidos como trabalhadores sociais atravessados pela causa analítica ${ }^{4}$. Como sinalizou o próprio Freud, é justificada a (re)criação de novos 'meios' de atuação, como se faz necessário em qualquer novo lócus de trabalho, desde que estejamos sempre firmes aos fins éticos da psicanálise ${ }^{5}$. De qualquer forma, mesmo não se tratando da psicanálise típica, e mais longe ainda da "psicanálise aplicada", o trabalho de Costa-Rosa (2013) coloca em perspectiva o que podemos melhor referir como "ampliação da psicanálise em intensão".

Ora, se as profissões típicas desse campo são práticas científicas a serem subvertidas, partindo de Marx que nos propõe a superação da divisão técnica do trabalho entre os que fazem e os que pensam, como trabalhadoresintercessores não estaríamos sendo coerentes tanto com Freud (1919/1996b), que vislumbrou a ampliação do tratamento analítico à classe trabalhadora de baixa renda $\mathrm{e}$ aos excluídos do trabalho, quanto com Lacan (1973/2003), para quem, além disso, interessava ainda uma prática científica que incluísse a psicanálise?

\section{AGRADECIMENTO IN MEMORIAM}

Tristemente, enquanto a editoração dessa resenha era finalizada ele "viajava antes do combinado". Se a sua vida corpórea chega ao fim não se pode dizer o mesmo do seu trabalho, fruto do um desejo decidido e coletivizado com o de tantos outros, que, por isso, continuará vivo e pulsante.
Cabe a nós, trabalhadores da causa psicanalítica e social, assumirmos o front e ocuparmos as tantas "brechas de transformação" que ele ajudou a vislumbrar.

Com carinho, ao "mestre" Abílio da Costa-Rosa.
3 Trabalhadores-intercessores, com a ressalva de que "o santo, para que me compreendam, não faz caridade. Antes, banca o dejeto" (Lacan, 1973, p. 518). Costa-Rosa pinça da filosofia de Deleuze (1992) a conceituação sobre "os intercessores" e a lê, redimensionando-a, a partir da psicanálise e do Materialismo Histórico, com o intuito de potencializar o seu alcance teórico-prático e ético-político.
4 Que Éric Laurent (1999), na tentativa de caracterizar uma certa variante destes, arriscou nomeá-los como "analistas-cidadãos".

5 "A possibilidade de influência analítica repousa em precondições [...] que podem ser resumidas sob a expressão 'situação analítica'; [...] Onde estas faltam [...] algo diferente da análise tem de ser utilizado, embora algo que seja uníssono com a análise em seu intuito" (Freud, 1925/1996, p. 314). 


\section{REFERÊNCIAS}

Costa-Rosa, A. (2012). Contribuição a uma clínica crítica dos processos de subjetivação na Saúde Coletiva. In G. H. Dionísio \& S. J. Benelli (Orgs.), Políticas públicas e clínica crítica (pp. 15-31). São Paulo: Cultura Acadêmica.

Costa-Rosa, A. (1987). Saúde Mental Comunitária: Análise dialética de um movimento alternativo (Dissertação de mestrado não publicada). Instituto de Psicologia, USP, São Paulo.

Costa-Rosa, A, Luzio, C. A., \& Yasui, S. (2003). Atenção Psicossocial: Rumo a um novo paradigma em Saúde Mental Coletiva. In P. Amarante (Org.), Archivos de Saúde Mental e Atenção Psicossocial (pp. 13-44). Rio de Janeiro: Nau.

Deleuze, G. (1992). Conversações. Rio de Janeiro: Editora 34.

Freud, S. (1996a). Prefácio à "Juventude Desorientada" de Aichhorn. In Edição standard brasileira das obras psicológicas completas de Sigmund Freud (Vol. 19, pp. 310-314). Rio de Janeiro: Imago. (Trabalho original publicado em 1925)

Freud, S. (1996b) Linhas de progresso da terapia psicanalítica. In Edição standard brasileira das obras psicológicas completas de
Sigmund Freud (Vol. 17, pp. 201-211). Rio de Janeiro: Imago (Trabalho original publicado em 1919).

Freud, S. (2014). Conferências introdutórias sobre psicanálise. In Obras Completas de Sigmund Freud (Vol. 13, pp. 13-630). São Paulo: Companhia das Letras. (Trabalho original publicado em 1916-17)

Kuhn, T. S. (1978). A estrutura das revoluções científicas. São Paulo: Perspectiva.

Lacan, J. (2006). Meu ensino. Rio de Janeiro: Jorge Zahar. (Trabalho original publicado em 1967-1968)

Lacan, J. (2003). Televisão. In Outros Escritos (pp. 508-543). Rio de Janeiro: Jorge Zahar. (Trabalho original publicado em 1973)

Laurent, E. (1999). O analista cidadão. Curinga, 13, 12-19.

Périco, W. (2014). Contribuições da psicanálise de Freud e Lacan a uma psicotherapia Outra: A clínica do sujeito na Saúde Coletiva (Dissertação de Mestrado). Universidade Estadual Paulista "Júlio de Mesquita Filho", São Paulo, SP, Brasil. 